\title{
Klossowski: Um fantasma entre Nietzsche e Foucault?
}

\author{
Klossowski: A ghost between Nietzsche and Foucault?
}

do) $10.21680 / 1983-2109.2021 v 28 n 57$ ID22108

\author{
Yolanda Gloria Gamboa Muñoz \\ Pontifícia Universidade de São Paulo (PUC-SP) \\ 0000-0001-5569-2727 \\ hilacha@uol.com.br
}

\begin{abstract}
Resumo: Após a montagem de um cenário fragmentário escolhendo determinadas expressões do pensamento de Klossowski sobre Nietzsche e assinalando um começo de leitura com duplo ponto de partida (de experiência pessoal e na via do Incipit), pretendo realizar um exercício de leitura textual utilizando uma expressão sobre Pierre Klossowski inscrita e mascarada por Foucault no Theatrum Philosophicum. Encaminho esse exercício de caracterização nominal - "um outro signo maior e excessivo" - fazendo determinadas referências ao papel do signo, do excesso e do gesto. Nosso suposto é que, ao considerar a apropriação foucaultiana deste signo gestual - sob o nome de Klossowski - seja possível desenhar uma fantasmagórica figura tríade apontando, de passagem, para um possível atravessamento, desvio e obstaculização de uma habitual relação simples e teórica entre os pensamentos de Nietzsche e de Foucault.
\end{abstract}

Palavras chaves: Klossowski; Nietzsche; Foucault.

Abstract: After the assemblage of a fragmentary scenario, selecting certain expression of Klossowski's thinking about Nietzsche and signaling a beginning of a reading with a double starting point (from personal experience and in the way of the Incipit), I intend to carry out an exercise of textual reading by making use of an expression of Pierre Klossowski that was inscribed and masked by Foucault in his Theatrum Philosophicum. I carry forward this exercise of nominal characterization -- "another great and excessive sign" - by making some references to the role of sign, of excess, and of gesture. Our purport is that taking into consideration Foucault's appropriation of this gestural sign - under the name of Klossowski - makes it possible to chart a phantasmagoric triad figure, pointing out, by the way, for a possible crossing, detour, and hindrance of a habitual relationship, simple and theoretical, between the thought of Nietzsche and that of Foucault.

Keywords: Klossowski; Nietzsche; Foucault. 
El esfuerzo que haga por tomar los recuerdos y lanzarlos al futuro, será como algo que me mantenga en el aire mientras la muerte pase por la tierra.

Felisberto Hernández

\section{MONTAGEM DE UM CENÁRIO.}

Se a complexa e desafiante tríade nominal constituída pelos personagens Nietzsche, Foucault e Klossowski precisa de um cenário de palavras onde seja possível esboçar alguns de seus gestos, tentaremos construí-lo, provisoriamente, como um solo esburacado que possa sustentar a si próprio por intermédio de determinadas expressões textuais.

Recolhamos, em primeiro lugar, da própria linguagem de Klossowski, seis expressões inscritas na sua polêmica leitura de Nietzsche. Podemos visualiza-las como "modelos de vida" dispostos no chão ao modo do "Mito de Er" de Platão (618 a), no qual, antes da próxima reencarnação, as almas escolhem seus atributos externos e do corpo, pois a areténão se escolhe (617e) e lembrando que, ao ter menos possibilidades ou ser o último a escolher, o profeta chama a escolher com coragem (619b) (Platão, 1983, p. 492-495). Acrescentemos que, sem inocência, esse Mito da escolha das almas será privilegiado por Klossowski na sua Introdução à tradução ao francês da Gaia Ciência, que ele realiza em 1957. Porém, não se trata de recolher essas frases dispostas no chão para que nos conduzam à procura de uma unidade, nem para aproximá-las entre si em função do critério de semelhança. Dito de outra forma, não podemos considerá-las "modelos" em sentido platônico. De modo que, tentando preservar sua singularidade, selecionaremos a seguir seis fragmentos de sua escrita, que ao modo do "reverso dos seis dias da criação do mundo" sejam possibilidades lançadas corajosamente ao porvir:

- "Há um instinto gerador de deuses que em Nietzsche é ao mesmo tempo vontade criadora e vontade de eternização" (...) "O não ensinável o atinge e alcança em sua solidão" (Klossowski, 1980, p.169) ${ }^{1}$

- "O Eterno retorno implica a abolição de toda vida pessoal restituída ao ser, para maior gloria do ser. Isso é o que ele quis ensinar, e que ele julgava digno de ser ensinado" (Klossowski, 1957, p. 34)

- "Zaratustra) por um lado é Cristo tal como o compreende Nietzsche secreta e cuidadosamente, mas, por outro lado, enquanto Acusador do Cristo tradicional, prepara o caminho para a chegada de Dionísio filósofo" (Klossowski, 1980, p.145)

- "A doutrina do Eterno retorno é um simulacro de doutrina cujo caráter paródico

\footnotetext{
${ }^{1}$ Quando as referências bibliográficas indicam o texto utilizado em francês ou espanhol as traduções são sempre nossas.
} 
dá conta até da hilaridade" (Klossowski, 1980, p.170)

- "O Eterno retorno de todas as coisas escolhe tornar-se em irrisão de sua própria doutrina (...) O Eterno retorno de todas as coisas quer também o retorno dos deuses" (Klossowski, 1980, p.171).

- "Ninguém incita tanto seu intérprete a lhe parodiar como Nietzsche" (Klossowski, 1980, p.143)

Neste pensamento singular, afastado da procura de uma unidade e que sem inocência acentua os antagonismos e os simulacros, encontramos entrelaçamentos de fios sutis, que em certas oportunidades nomeiam três virtudes cardeais em Nietzsche: as forças de eternização, de adoração e de criação (Klossowski, 1980, p.171) ou que consideram um todo indissolúvel: o pensamento lúcido, o delírio e o complot (Klossowski, 1969, p. 12) e que, outras vezes, irrompem saltando parodicamente desde a Gaia ciência até a Consideração Extemporânea II (Klossowski, 1957, p.10 e11)para assinalar, nesse escrito de 1876, um triângulo do Saber: Instante, Esquecimento e Vontade. Instante, aliás, explicitado como possibilidade de sentir fora da história e vive-lo diferentemente, segundo se trate do animal, da criança e do homem adulto (esse último carregando os espectros do passado, tendo assim devorada a calma do instante posterior). No entanto, a possibilidade de pensar a história composta de atos e criações surgidas do esquecimento mostraria uma estreita relação (rapport) entre esquecimento e querer criador. Leitura também tripla que lhe faz vislumbrar, já nesse espaço da Segunda Extemporânea, o estímulo da noção de Eterno Retorno como possibilidade fora da história e assim relacioná-lo à faculdade de esquecer. Klossowski vai desenhando, dessa forma e de muitas outras, por intermédio de um pensamento literário-filosófico, uma espécie de percurso tortuoso que faz com que à luz dessa leitura Nietzsche, promova primeiramente uma "autoverificação" em sua própria existência, para logo descobrir sua própria fatalidade e, finalmente, exteriorizar-se num "acontecimento capital": Zaratustra.

E como se posiciona Foucault diante dessa polêmica leitura relacional? Produzindo novos fios discursivos que se somam e contribuem para cobrir esse chão esburacado mediante outras tríades interpretativas. Isso palpita, a meu ver, não somente no texto explicitamente dedicado a Klossowski, La prose d'Actéon, mas numa espécie de fantasma de Klossowski que permanece acompanhando-o e movimentando-se à sombra de seus escritos. Prova gestual, por exemplo, é a silenciosa irrupção e interrupção da "mão de Roberte" (Foucault, 1994c, p.80) anos após ter realizado a descrição explícita e ambígua daquela "Roberte com duas existências ou de duas Roberte com uma existência” (Foucault, 1994 a, p.333) Mas ao ficarmos nessas considerações "perigosas" poderíamos ser conduzidos ao afastamento 
das sérias analises textuais. No entanto, pensamos que em Foucault a valorizada leitura textual é substituída pela murmuração constante da materialidade discursiva, o que leva-nos a reparar, precisamente, em determinadas superficialidades de inscrição ao modo de "assinaturas sobre cheques" (Foucault,1994 a, p.331): o nome de Klossowski será inscrito por Foucault numa nova trilogia, em diversas oportunidades, em suas referências a Bataille, Blanchot e Klossowski. Na discursografia foucaultiana haverá também uma serie de gestos repetitivos, que, ao nosso ver, acompanham e duplicam a leitura nietzscheana de Klossowski. Na impossibilidade de explicitá-los, nesta ocasião, limitemo-nos a sua superficial nomeação gestual repetitiva onde, ao nosso ver, a sombra de Klossowski acompanha determinados procedimentos foucaultianos: a parodia genealógica e histórica para tratar da genealogia em Nietzsche; o salto aparentemente arbitrário desde a Genealogia de Moral até a Consideração Extemporânea II ; a constante retomada do aforismo 333 da Gaia Ciência; o recolher "personagens não profundos" mas destinados ao esquecimento como na Vida dos Homens Infames; o uso da nomeação Vontade de Saber ; a prática do desvio afirmativo até na filosofia da história de Hegel; e, também, o que já tem sido pertinentemente assinalado, a decisão filosófica de devolver ao simulacro sua potência perturbadora e seu tornar-se ilimitado instaurando a destruição de modelos e cópias, decisão que operaria na intermediação (relais)implícita do simulacro em Isto não é um cachimbode Foucault (Sabot, 2004, p.15) ${ }^{2}$.

Gestos e procedimentos que caminham junto ao apagamento constante de possíveis "identidades" incluindo o próprio discurso. Apagamento que, em Foucault, está em relação com a autotransformação nos seus escritos, ao modo talvez de Actéon que, na última metamorfose, torna-se "impuro, frenético e deliciosamente profanador" (Foucault, 1994 a, p.327) Nesse sentido, podemos retomar uma das últimas transformações ou figuras-construto foucaultianas, localizada na Introdução ao Uso dos prazeres, isto é, um de seus últimos gestos inscritos na materialidade discursiva, a partir do qual considera a filosofia como exercício:

Mas o que é a filosofia hoje em dia - eu quero dizer a atividade filosófica - se ela não é o trabalho crítico do pensamento sobre si mesmo? E se ela não consiste, em lugar de legitimar o que já se sabe, no empreendimento de saber como e até onde seria possível pensar de outra maneira? (Foucault,1984, p.14-15)

Por isso, será retomando essa última nuance reflexiva que procederemos no exercício proposto para essa ocasião, recolhendo e repetindo a caracterização de

\footnotetext{
${ }^{2}$ A numeração da página corresponde a uma cópia do artigo fornecida gentilmente pelo autor e pode não corresponder ao original da Revista Concepts.
} 
Klossowski contida nos bastidores do Theatrum Philosophicum. Mas, antes da realização do exercício, debrucemo-nos nas possiblidades dos começos que nesta constelação discursiva não poderiam se instaurar, mas proliferar.

\section{UMA DUPLICIDADE NOS COMEÇOS.}

\section{a) Experiência pessoal ou um gesto de solipsismo?}

Ao materializar a leitura de Klossowski sobre Nietzsche e o privilégio que Klossowski daria à experiência, segundo sublinha Foucault, limito-me a executar um gesto de abrir as mãos escolhendo começar por uma autoverificação experiencial marcando assim uma modificação de minhas próprias pesquisas "com" e "entre" os escritos de Foucault. Rastros da relação com o pensamento de Foucault que nos remetem aos anos 70, no Chile, numa época em que oficializar a leitura de Foucault constituía um desafio, pois a direção da Universidade de Chile acabava de rejeitá-lo para ministrar cursos como professor visitante (Muñoz, 2019, p.159). Continuei minhas pesquisas de aproximação ao transformável pensamento de Foucault, aqui no Brasil, oficialmente a partir do ano 1987, quando retomei o trabalho acadêmico, como estudante, tentando desenhar possíveis relações entre os escritos de Nietzsche e Foucault ${ }^{3}$, incluindo muitos rastros intermediários, principalmente aqueles de Bataille, Blanchot e Deleuze. Longo trajeto em que pesquisei a problemática da escolha na filosofia, forte em Nietzsche, mas não em Foucault, demorando para perceber que o escolher constituía uma temática ou doação de Paul Veyne aos percursos foucaultianos. Nessas pesquisas a escolha do Mito de Er de Platão constituiu sempre um cenário inaugural.

Porém, através de muitos desses caminhos e desvios, fui assinalando constantemente a desconfiança materializada nos livros publicados de Foucault, suas armadilhas discursivas, seu apagamento e desprendimento (effacement et détachement) proposital de si mesmo como autor, mas sem relacioná-lo ao que gostaria de destacar atualmente repetindo a própria denominação de Foucault "um outro signo maior e excessivo" (que estava ao lado do signo Deleuze!), com o qual me refiro ao nome de Klossowski. Nome que hoje avalio como um signo gestual de interrogação a ser reintroduzido na discursografia foucaultiana, sobretudo quando se trata de avaliar a leitura e apropriação que Foucault realiza do pensamento de Nietzsche. É só agora que a escolha do daimon, a declaração da Virgem

\footnotetext{
${ }^{3}$ Nessa época pretendia mapear “As seleções nietzscheanas de Foucault”, o que em determinado estágio do percurso transformaram-se em "As seleções foucaultianas de Nietzsche” e que, finalmente, sob uma outra nomeação, formaram parte do material de uma dissertação.
} 
Láquesis, o ciclo das reencarnações e o esquecimento descobrem a figura de "a inversão como num espelho" com "O mais pesado dos pesos" e o "Eterno Retorno", para me referir só a um dos sutis fios que atravessam o pensamento de Klossowski sobre Nietzsche.

Sem querer permanecer nesse território de experiencias "auto-referentes", mesmo simulando um gesto caro a Klossowski e situando-nos à sombra de uma pretensa "auto-crítica" - talvez localizada entre o Solipsismo e o Selbsucht - salto até um outro tipo de começo que consegue romper identidades até experienciais.

\section{b) $O$ Incipit}

Retomando uma expressão do artigo de Foucault sobre Klossowski, La prose d'Actéon, de 1964, isto é, seis anos anterior ao Theatrum Philosophicum, encontramos nele a expressão: "Incipit Klossowski, como Zaratustra" (Foucault, 1994 a, p. 327).

Lembremos que na utilização do Incipit Zaratustra realizada por Nietzsche no Crepúsculo dos Ídolos, especificamente no sexto cenário da "História de um erro ou Como o verdadeiro mundo acabou por se tornar fábula"(Nietzsche, 1973, p. 58) é possível constatar que o Incipit Zaratustra desse $6^{\circ}$ cenário, utilizado por Nietzsche em latim (desviando-se de um simples começo em alemão: Anfang, Beginn), indica uma possível ligação com as reflexões sobre a transubstanciação e o movimento angélico. Para avaliar o peso dessa expressão, vale a pena lembrar que no século XIII e XIV sua utilização, como estudo lógico dos termos ou na via de uma teoria de interpretação das proposições (incipite desinit), reunia uma convergência lógica, física e ontológica; solidariedade que reconhecia a interação entre 'o instante da mudança' e a atomicidade e continuidade do tempo físico em extenso. Teorias inseparáveis do estudo das denominadas mudanças paradoxais da transubstanciação e do movimento angélico.

Nesse sentido teríamos que nos perguntar em que direção aponta o gesto de Foucault, ao repetir a expressão de Nietzsche sobre Zaratustra, mas aplicada a Klossowski: "Incipit Klossowski, como Zaratustra". Transubstanciação? Movimento angélico? Em todo caso e, nesta via, seria pertinente repetir, o que já foi dito na construção do cenário, Klossowski considerava Zaratustra como "acontecimento capital" por intermédio do qual Nietzsche consegue a exteriorização, isto é, abandonar a autoverificação solitária e o reencontro com sua própria fatalidade. Gesto de exteriorização? Abandono de um possível solipsismo? Sem uma tentativa de resposta podemos introduzir uma irrupção textual do solipsismo do próprio 
Klossowski, que, na Revogação do Edito de Nantes é amplificada para tratar da contradição de gestos e palavras:

\begin{abstract}
Alguns pensam que se comete solipsismo também com o gesto, cada vez que mediante um movimento da cabeça ou da mão se faz entender o contrário do que se diz. A que se refere essa frase de Quintiliano, que uso como epígrafe do catálogo razoado de minha coleção de quadros? Suponho que ao tema de mais de uma das obras do mestre desconhecido que figuram em minha coleção.

Em princípio, não se vê muito bem a relação estabelecida entre o gesto e a palavra, sobretudo quando não se trata somente de alguns gestos que constatamos, efetivamente, em várias das figuras representadas. Onde entra a palavra? Sem dúvida naquilo que o pintor supõe que seus personagens dizem, não menos naquilo que o espectador diz ao contemplar a cena. Mas se o solipsismo é cometido, se é algo oposto ao que as figuras dão a entender mediante qualquer gesto, é necessário que algo seja dito, para que esse oposto seja sensível: ao estar pintadas, calam-se. (Klossowski, 1975, p.11-12.)
\end{abstract}

\title{
III UM EXERCÍCIO ENTRE NIETZSCHE-FOUCAULT: SIGNO, EXCESSO E GESTO
}

\section{a) $\mathbf{O}$ signo}

Tendo como primeira camada do cenário do signo a cuidadosa distinção entre signo (profético e irónico ao mesmo tempo) e simulacro (que teria a peculiaridade de não determinar um sentido) realizada por Foucault em La prose d'Actéon, escolhemos, no entanto, recolher elementos em camadas discursivas "posteriores" para nos aproximar do papel do signo (e assim de Klossowski como signo). Recolho a seguir e brevemente algumas materialidades discursivas que explicitam a própria utilização foucaultiana do signo, principalmente em "Nietzsche, Freud e Marx", na Ordem do Discurso e nas referências a Paul Klee.

Em "Nietzsche, Freud e Marx" é possível constatar que a análise do século XVII mostra como as técnicas de interpretação e as teorias do signo repousavam, nesse período, sobre a semelhança. Isso por que desde o século XVI havia um espaço homogêneo de repartição em que os signos iam da terra ao céu, de maneira que reenviavam uns aos outros. Diferentemente, no século XIX, Nietzsche, Freud e Marx mudariam tanto a natureza do signo, como o espaço de repartição no qual os signos podem ser signos. Assinaladas as especificidades de Marx, Nietzsche e Freud, será afirmado nesse escrito, que todos eles contribuíram a pensar os signos como uma rede infinita, sendo que cada signo se mostra como interpretação de outros signos, deixando aparecer o jogo violento das apropriações. Dessa maneira e, resumidamente, podemos dizer que essa análise foucaultiana faz cair o véu dos 
signos e Foucault poderá afirmar que "não há signos primeiros e enigmáticos", mas um tecido de interpretações violentas. É a interpretação que precede o signo, de maneira que "os signos são interpretações que ensaiam se justificar e não ao inverso". Destaquemos que, à margem, mas em estreita ligação, o próprio artigo "Nietzsche, Freud e Marx" é montado na "imagem" do vulcão, sendo que nele e em relação a Nietzsche e Freud, a "experiência da loucura seria a sanção de um movimento da interpretação que se aproxima do infinito de seu centro e afunda-se, calcinada" (Foucault, 1994b, p.571).

Já na Ordem do Discurso existe uma referência não inocente a três signos para o trabalho diário: Nietzsche, Artaud, Bataille (Foucault, 1971, p. 22-23). Nesta série teríamos que situar Klossowski como signo? Interrogante diante da qual poderíamos nos desviar para seguir as pegadas de Paul Klee, pois esse pintor, segundo Foucault, recolhe espacialmente o signo em seu modo de ser signo e não em sua suposta capacidade de dar um sentido:

\begin{abstract}
Klee extrai da aparência do mundo uma série de figuras que tinham valor de signo e dispõe as figuras harmonicamente dentro de um espaço pictórico, conservando sua forma e estrutura de signos, quer dizer, mantendo seu modo de ser como signos e, ao mesmo tempo, atuando de maneira que não tivessem significado. Como não sou nem estruturalista nem linguista me extasio diante de uma utilização semelhante do signo; quer dizer, no signo no seu modo de ser signo e não na sua capacidade de dar o sentido" (Caruso, 1969, p.83).
\end{abstract}

De modo que, a partir das referidas materialidades discursivas, é possível dizer que a utilização do signo na discursografia de Foucault, não guarda relação com a semelhança, com um sentido, ou com um signo primeiro, à medida que o signo se inscreve, precisamente, como afastamento de sua relação com o significado (Muñoz, 2018, p. 25) e, segundo sua própria declaração posterior, para afastar-se do que na sua atualidade se tornou habitual, torna-se necessário "não tratar do sistema dos signos - (o significado) com grande respeito" ${ }^{4}$.

\title{
b) $O$ excesso
}

Sem dúvida o excesso constitui um tema relacionado às problemáticas do signo e do Incipit. Porém esse excesso (pensado como sobreabundância, mehr e über) só poderia ser avaliado ao acrescentarmos determinadas considerações diferenciais sobre o Übermensch e sobre Zaratustra, quando provenientes da boca de Nietzsche, de Klossowki ou de Foucault. Tarefa impossível de mapear nesta

\footnotetext{
${ }^{4}$ Foucault refere-se a essa luta contra o que na sua época tornava-se habitual marcando três alvos: sair da intimidade com Marx, afastar os sonhos de Freud e não tratar os "sistemas de signos" (o significado) com grande respeito. (Foucault, 1994e, p.133)
} 
ocasião. Contentemo-nos em assinalar um aspecto dessa problemática ao considerarmos que, para Klossowski, o Übermensch não constitui um indivíduo, mas um estado fantasmagórico que dá um sentido à existência e fixa uma meta a seguir. (Klossowski, 1969, p. 217).

Nessa perspectiva nossa referência é o texto de Foucault que sustenta muitos elementos das referidas análises do signo e do excesso em cruzamento: o Theatrum Philosophicum. Segundo nossa avaliação atual há muitos níveis possíveis de assistir ou de ler o roteiro do Theatrum Philosophicum, uma vez que se trata de uma leitura material e seriamente reflexiva e problematizadora sobre dois livros de Deleuze (Lógica do Sentido e Diferença e Repetição). Através dessa leitura, Foucault enfatiza o acontecimento (événement) marcando três recentes tentativas fracassadas de pensa-lo: o neopositivismo, a fenomenologia e a filosofia da história, tratando, nesse mesmo texto, da necessidade de invenção e das dificuldades do pensamento a-categórico para, finalmente, acabar inscrevendo o Eterno Retorno de Nietzsche como um excesso, ao que não se pode emprestar conteúdos, um insuportável de pensar. Também podemos ler o Theatrum Philosophicum como um espaço privilegiado que mascara uma reflexão sobre o tempo; que considera um "eterno presente", no qual o presente é pensado sem plenitude e o eterno sem unidade. Outrossim, é possível caminhar entre essas camadas teatrais e realizar, ainda, uma outra leitura. Se repararmos no jogo constituído pelas palavras iniciais e finais dessa encenação, vislumbraremos um nível mais esquecido e alegremente superficial, inscrito no gesto que constitui e impulsiona o próprio roteiro, capaz de fazer pulsar máscaras atrás de máscaras, "o segredo de ser sem segredo", procedendo rousselianamente, isto é, como no Raymond Roussel foucaultiano (Muñoz, 2013, p. 272-275) sendo "impossível decidir se há um segredo ou vários e quais são "(Foucault, 1963, p.19).

Dessa forma, encontramos a presença de um signo duplo, que aparece no começo, no meio e no fim desse teatro: Klossowski, por trás da máscara de Deleuze e de Nietzsche. No começo da encenação, os dois grandes livros de Deleuze e o próprio personagem Deleuze, aparecem em "ressonância enigmática" com esse outro "signo maior e excessivo": Klossowski. No fim da encenação, vários filósofos mascarados em suas próprias filosofias e ligados teatralmente entre si como "mimos em cenas múltiplas, fugitivas e instantâneas, nos quais os gestos, sem se ver, fazem signos" de forma a fechar esse Theatrum com "os bigodes (moustaches) de Nietzsche, disfarçado (déguisé) de Klossowski" (Foucault, 1994c, p.99). E no meio, muitas ressonâncias enigmáticas: o simulacro, o fantasma, e, talvez, o círculo vicioso do retorno. Material e corporalmente, na companhia de Bataille e Sade, trazendo a palma virada (renversée) num gesto de defesa que, ao mesmo tempo, se oferece: Roberte. Mais uma vez Klossowski, caracterizado por Foucault como "aquele que trata sua própria linguagem como simulacro", desta vez na série do ateísmo e da transgressão, surgindo mascarado como Roberte! Como já dissemos 
no começo, no item sobre o Incipit, Foucault já tinha afirmado 6 anos antes (1964), mesmo sem ser ouvido: Incipit Klossowski, como Zaratustra. (Foucault, 1994 a, p.327), mas suspeitamos que a presença do simulacro vai além desse Theatrum e do Incipit. Ela poderia constituir e auto constituir-se transversalmente nas dobras da própria discursografia foucaultiana, pois, como diz Klossowski "nós conhecemos nosso mecanismo; é preciso desarticulá-lo"(Klossowski, 1969, p.181).

\section{c) 0 gesto}

Finalmente, na análise dos gestos enfatizemos como, para o Foucault do Theatrum Philosophicum, os gestos mímicos entre os filósofos mascarados não são vistos, mas fazem signos.... Até agora nossa referência principal e textual ao gesto tem sido a problemática do gesto divergente em Nietzsche e Foucault (Muñoz, 2017, p. 211, 216-217). Porém, ao vislumbrar o entre-Klossowski proposto como um entre-dois ${ }^{5}$, teríamos que retomar também a via gestual. Para isso, recolheremos a conceptualização do gesto que nos parece centelhar materialmente nas análises do cineasta Raúl Ruiz, que levou ao cinema em 1978 La vocación suspendida, de Klossowski e dirigiu em 1979 A hipótese do quadro roubado, filme sobre o próprio Klossowski. Salientemos que, nesse último filme, "todos os personagens têm os mesmos gestos, caem nos mesmos gestos e que o eterno é o gesto. Não é a pessoa ou o personagem que é eterno, mas o gesto mesmo". (Ruiz, 2013a, p. 280). Outrossim, ainda segundo Raúl Ruiz, tudo o que se faz é eterno, porque, mais cedo ou mais tarde, um gesto já foi feito por um outro, o que forma uma ponte entre todos esses momentos e oferece um sentimento de eternidade. De modo que, mediante essa problemática, o referido cineasta costuma fazer emergir determinadas relações entre ironia, piadas filosóficas e gratuidade, que pensamos pertinentes de serem introduzidas à constelação Nietzsche/ Klossowski/ Foucault.

Cabe acrescentar, nesse sentido, que Klossowski, em Roberte ce soir, mostrou-se um sutil estudioso dos gestos diferenciais de ambas as mãos: há, ao mesmo tempo, uma mão que aceita e outra que rejeita; gestos constantes e simultâneos da própria Roberte, que direcionam até a problemática do solipsismo e parecem estar presentes, em primeiro plano, quando Klossowski e Foucault lidam com a doutrina do Eterno Retorno como círculo vicioso e simulacro. Nesse aspecto e novamente situados no cenário do Theatrum Philosophicum, teríamos que considerar a distinção que, nessa ocasião, realiza Foucault entre as apropriações filosóficas do Eterno Retorno. De um lado há os que lhe emprestam conteúdos míti-

\footnotetext{
${ }^{5}$ Como disse pertinentemente Francisco Varela, “ (Merleau-Ponty) o único em seu tempo que aponta para esse problema de topologia do entre-dois (...) limitação (...) na tradição ocidental, ainda que possamos falar desse entre-dois, não temos muitos meios de explorá-lo realmente, de fazer uma prática do sujeito, como diria Foucault, para trabalhar com isso. (...) interessa-me muito a tradição oriental, porque nela temos uma teoria de um descentramento do sujeito enormemente elaborada com uma pragmática de dois mil anos” (Varela, 1993, p.88)
} 
cos, procurando desarmá-lo e reduzi-lo. Isto é, os que procuram um significado arbitrário. De outro lado estariam os que tratam de poli-lo, para que adquira um lugar não vergonhoso no fio do discurso. Isto é, os que querem constituir com ele uma palavra. Finalmente, teríamos os que o consideram um signo excedentário, sempre deslocado, que falta indefinidamente ao seu lugar. Nesse último caso - que poderíamos entender como o de Deleuze, Klossowski e Foucault - só ficaria a ressonância como um voltar da diferença. De modo que o retorno - como signo excedentário - não seria a forma de um conteúdo entendido como a diferença. Seria uma diferença, porém sempre nômade, sempre anárquica. Um signo, claro, mas sempre em excesso, signo deslocado do voltar.

\section{UM GESTO TRIANGULAR}

Após percorrer alguns rastros de escrita ignoramos ainda se existe a possibilidade de lidar, pertinentemente, com a sombra fantasmagórica de Klossowski. Um de seus personagens, um escritor de resenha de um livro inexistente, insiste em assinalar seriamente, citando Eliot:

A perda progressiva no leitor moderno que, longe de seguir ao autor nos descobrimentos de seu trabalho, não busca senão reviver a experiência em bruto, a coincidência do que está escrito com o que ele mesmo tem experimentado, e assim se torna incapaz de passar à realidade segunda e entrar na Terra Prometida que oculta toda criação autêntica (Klossowski, 1975b, p.16)

Porém, não desistiremos facilmente e nos somaremos à resistência hilária praticada por Raúl Ruiz nas montagens cinematográficas que apresentam cenas vivas a partir de quadros pintados e com a constante presença das máscaras, assinalando assim sua própria e divertida desconfiança diante da ambiguidade dos personagens de Klossowski. Personagens que, num dado momento, declaram algo seriamente, para logo se tornarem o oposto de sua declaração; pensemos nos seminaristas que se tornam oficiais nazis, por exemplo, pois esses personagens ou Homens-Simulacros (como os denomina Foucault) seriam bem mais vertiginosos que os rostos pintados das divindades. "São seres perfeitamente ambíguos, pois falam e fazem gestos, piscam os olhos (des clins d'yeux), agitam seus dedos e surgem nas janelas como semáforos (para lançar signos ou dar a impressão que os enviam quando eles fazem somente simulacros de signos?)" (Foucault, 1994 a, p. 332).

É nesta atmosfera que acrescentaremos ainda uma nota final, reforçando a irrupção e a presença do simulacro contidas nas ordenações dos livros de Foucault. Na carta a Klossowski de 1970, Foucault diz não tratar-se de um agradecimento ou reconhecimento pelo que Klossowski nos fez... pois ele foi além (au-delà); Foucault não somente reconhece ter lido várias vezes La monnaie vivante, caracterizada 
como "o mais alto livro de nossa época" (Foucault, in: Klossowski, 1997, p.9) capaz de nos conduzir insidiosamente ao que em nossa atualidade conta de uma maneira ou de outra (Blanchot, Bataille e Para além do Bem e do Mal), como também desenha o que nos domina e nos constitui há séculos, o triângulo histórico: desejo, valor e simulacro. Triângulo que, após o livro de Klossowski, La monnaie vivante, nos permite rir daqueles que simplesmente dizem Freud-e-Marx (podemos pensar na falta de Sade e Para além do Bem e do Malao percorrermos as páginas desse texto). Porém, com distância, e como leitores de Foucault, podemos nos perguntar se ainda não nos falta avaliar na sua própria discursografia a presença do terceiro ângulo. Em outras palavras, falta pensar e pesar o simulacro discursográfico? Difícil tarefa, para a qual, talvez tenhamos que continuar além da toupeira, e começar novamente a escavar o "Incipit Klossowski, como Zaratustra", agora como um entre, signo gesto excessivos.

\section{REFERÊNCIAS}

CARUSO, Paolo. Conversación con Michel Foucault. In: Caruso, P. Conversaciones con Lévi-Strauss, Foucault y Lacan. Trad. F. Serra Cantarell, Barcelona, Ed. Anagrama, 1969, p. $65-91$.

FOUCAULT, Michel. Raymond Roussel. Paris, Gallimard, 1963.

FOUCAULT, Michel. L'ordre du discours. Paris, Gallimard, 1971.

FOUCAULT, Michel. L'usage des plaisirs. Histoire de la sexualité II. Paris, Gallimard, 1984.

FOUCAULT, Michel. Dits et écrits. Paris, Gallimard, 1994. 4 v.

FOUCAULT, Michel. La prose d'Actéon. In: Dits et Écrits I, Paris, Gallimard, 1994a, p. 326337.

FOUCAULT, Michel. Nietzsche, Freud e Marx. In: Dits et Écrits I, Paris, Gallimard 1994b. p. 564-579

FOUCAULT, Michel. Theatrum philosophicum. In: Dits et Écrits. II, Paris, Gallimard, 1994c, p.75- 99.

FOUCAULT, Michel. Nietzsche, la généalogie, l'histoire. In: Dits et Écrits. II, Paris, Gallimard 1994d, p.136-156.

FOUCAUlT, Michel. Préface. In: DELEUZE, Gilles, GUATTARI, Félix. Anti-Oedipus: Capitalism and Schizophrenia. Trad. F. Durand-Bogaert. New York, Viking Press, 1977; reproduzido in Dits et écrits, III, Paris, Gallimard 1994e, pp. 133-35.

FOUCAULT, Michel. Leçons sur la volonté de savoir. Paris, Gallimard, 2011.

KLOSSOWSKI, Pierre. Roberte ce soir. Paris, Les ed. De Minuits, 1953.

KLOSSOWSKI, Pierre. Introduction. In: NIETZSCHE, Friedrich. Le Gai Savoir, trad. P. Klossowski, Club Français de Livre, 1957.

KLOSSOWSKI, Pierre. Nietzsche et le cercle vicieux. Mercure de France, Paris, 1969. 
KLOSSOWSKI, Pierre. La revocación del Edicto de Nantes. trad. M. Alban e J. García Ponce, México, Ed. Eras, 1975a.

KLOSSOWSKI, Pierre. La vocación suspendida. trad. Michel Alban e Juan García Ponce, México, Ed. Eras, 1975b.

KLOSSOWSKI, Pierre. Nietzsche, el politeísmo y la parodia. In: Tan funesto deseo, trad. M. Armiño, Madrid, Taurus, 1980.

KLOSSOWSKI, Pierre. La monnaie vivante. Rivages poche, Paris, 1997.

MUÑOZ, Yolanda Gloria Gamboa. Foucault: o outro que passa por nós. In: $O$ mesmo e $o$ outro, 50 anos da História da Loucura, S. T. Muchail, M. A. da Fonseca, A. Veiga-Neto (org.) Belo Horizonte, Autêntica Editora, 2013, pp. 269-281.

MUÑOZ, Yolanda Gloria Gamboa. Nietzsche, a fábula ocidental e os cenários filosóficos. São Paulo: Paulus, 2014.

MUÑOZ, Yolanda Gloria Gamboa. Foucault: um alquimista rebelde? In: Michel Foucault $e$ as insurreições: É inútil revoltar-se? Org. M. Rago e S. Gallo, São Paulo, Intermeios, 2017. pp. 209-222.

MUÑOZ, Yolanda Gloria Gamboa. Ariadna: ¿Un signo para Foucault?, Revista Dorsal, vol. 4, série 1, 2018, p. 11-30. Disponível em: http://www.revistas.cenaltes.cl/index.php/dorsal MUÑOZ, Yolanda Gloria Gamboa. Entrevista 2018 (p.159 e 173) In: SANCHEZ, Nicolás Fuster e TELLO, Andrés Maximiliano (Ed.) Subversión Foucault. Usos teórico-políticos, Ed. Metales Pesados, Santiago de Chile, 2019.

NIETZSCHE, Friedrich. Also sprach Zarathustra, Bonn: Insel Verlag, 2007./Ainsi parlait Zarathoustra /Also sprach Zarathustra. Trad. de G. Bianquis. Paris:Aubier- Flammarion, 1969, 2 vols. (éd. bilingüe). / Así habló Zaratustra. Trad. de A. Sánchez Pascual. Madrid: Alianza, 1972.

NIETZSCHE, Friedrich. Par delà le bien et le mal/Jenseits von Gut und Böse. Trad. G. Bianquis. Paris: Aubier, (éd. bilingüe), 1978.

NIETZSCHE, Friedrich. Le gai savoir. Trad. de P. Klossowski. Paris, Union Général d'Éditions, 10/18, 1957./ Die fröhliche Wissenschaft. Stuttgart, Insel Verlag, 1982.

NIETZSCHE, Friedrich. Obras incompletas. Trad. R. R. Torres Filho. $3^{\mathrm{a}}$ ed. São Paulo: Abril Cultural, 1983.

NIETZSCHE, Friedrich. Crepúsculo de los ídolos. Trad. de A. Sánchez Pascual. Madrid, Alianza, 1973/ Götzen-Dämmerung., Stuttgart, Insel Verlag, 1985.

NIETZSCHE, Friedrich. Ecce Homo. Frankfurt: Insel Verlag, 1977

NIETZSCHE, F Ecce Homo, Trad. A. Sánchez Pascual, Madrid: Alianza Editorial, 1998.

NIETZSCHE, Friedrich. Morgenröte. In: Kritische Studienausgabe (KSA 3). Herausgegeben. Von G. Colli und M. Montinari. München, DTV / W. De Gruyter, 2008.

Platão. A República. Trad. de Maria Helena da Rocha Pereira. Lisboa, Fundação Calouste Gulbenkian, 1983. 
RUIZ, Raúl. Entrevistas escogidas, filmografia comentada, Santiago, Ed. Universidad Diego Portales, 2013a.

RUIZ, Raúl. Poéticas del cine, trad. Alan Paulus, Santiago de Chile, Ed. Universidad Diego Portales, 2013b.

SABOT, Pierre. «Foucault, Deleuze et les simulacres » in : Concepts $\mathrm{N}^{\circ} 8$ : « Gilles Deleuze, Michel Foucault : continuité e disparité », Sils Maria ed., Vrin, mars 2004, p. 3-21.

VARELA, Francisco. Entrevista in: R. da Costa (org.), Limiares do contemporâneo. Entrevistas. Escuta, São Paulo, 1993. 